\title{
Eficiência na seleção de progênies de cafeeiro avaliadas em Minas Gerais
}

\author{
Marcelo Frota Pinto (1); Gladyston Rodrigues Carvalho (2); César Elias Botelho (2); Flávia Maria \\ Avelar Gonçalves ( $\left.{ }^{3}\right)$; Juliana Costa de Rezende $\left({ }^{2 *}\right)$; André Dominghetti Ferreira $\left({ }^{2}\right)$
}

(') Universidade Federal de Lavras (UFLA), Departamento de Agricultura, Programa de Pós-graduação em Fitotecnia, Caixa Postal 1337, 37200-000 Lavras (MG), Brasil.

(2) Empresa de Pesquisa Agropecuária de Minas Gerais (Epamig), Unidade Regional do Sul de Minas. Caixa Postal 176, $37200-000$ Lavras (MG), Brasil.

(3) UFLA, Departamento de Biologia, 37200-000 Lavras (MG), Brasil.

(*) Autora correspondente: julianacosta@epamig.br

Recebido: 18/maio/2011; Aceito: 2/nov./2011

\begin{abstract}
Resumo
O presente trabalho teve como objetivo verificar a eficiência de seleção das progênies de cafeeiros derivadas do cruzamento entre Catuaí com Icatu e com Híbrido de Timor. Foram avaliadas 18 progênies desenvolvidas pelo Programa de Melhoramento Genético da Epamig/UFLA/UFV. Os ensaios foram instalados em dezembro de 2005, nas cidades de Lavras, Campos Altos e Patrocínio, em Minas Gerais. As características analisadas foram as seguintes: produtividade, grãos retidos em peneira “17 acima” e frutos cereja em porcentagem. Para verificar a eficiência de seleção, foi aplicado o índice de coincidência segundo métodos de HAMBLIN and ZIMMERMANN (1986) e a magnitude da interação progênies x ambientes e sua decomposição em parte simples e complexa utilizando método de CRUz e CASTOLDI (1991). A predominância da parte complexa em relação à simples na interação das progênies x ambientes confirma a baixa ou não coincidência das progênies nos diferentes ambientes, dificultando uma recomendação generalizada para as diferentes regiões cafeeiras do Estado.
\end{abstract}

Palavras-chave: Coffea arabica, índice de coincidência, interação progênies x ambientes.

\section{Selection efficiency of coffee progenies evaluated in the State of Minas Gerais, Brazil}

\section{Abstract}

The present work had the aim of verifying the selection efficiency of coffee plants originated from the crossing between Catuaí and Icatu with Timor Hybrid. Eighteen progenies developed by the Program of Genetic Improvement of Epamig/UFLA/ UFV were evaluated. Coffee plants were planted in December 2005 in the following counties: Lavras, Campos Altos and Patrocínio, in the State of Minas Gerais. The characteristics analyzed were: productivity, grain size and proportion of cherry fruit. In order to verify the efficiency of the selection, the index of coincidence was applied according to the methodology of HAMBLIN and ZIMMERMANN (1986), as well as the magnitude of the interaction progenies $x$ environments and its decomposition in simple and complex parts using the methodology of CRUZ and CASTOLDI (1991). The predominance of the complex part in relation to the simple one in the interaction of the progenies $x$ environments confirms the low or absence coincidence of the progenies in different environments, raising difficulties for a general recommendation for different coffee regions in the State of Minas Gerais.

Key words: Coffea arabica, index of coincidence, interaction progenies x environments.

\section{INTRODUÇÃO}

A seleção e recomendação de genótipos mais produtivos são objetivos básicos dos programas de melhoramento genético de qualquer espécie cultivada. A avaliação de progênies em vários locais é uma etapa importante na fase final de um programa de melhoramento genético de plantas, pois com esse recurso, é possível determinar a interação dos genótipos com os ambientes e no caso da existência desta, fornecer subsídios para a recomendação técnica de cultivares para locais específicos.
Essa interação não interfere apenas na recomendaçẫo de cultivares, mas também dificulta o trabalho dos melhoristas, que precisam adotar critérios diferenciados para selecionar genótipos superiores e usar métodos alternativos de identificação de material de alto potencial genético (Silva et al., 2008; Vasconcelos et al., 2010). Em razão da relevância desta interação, é necessário obter informaçôes sobre sua magnitude e natureza, para permitir a melhor estratégia de seleção. O conhecimento aprofundado de suas causas e consequências minimiza os prejuízos e maximiza o uso de recursos e o retorno ao 
agricultor. Quando se dispóe de uma rede de ambientes para avaliaçáo dos genótipos, torna-se fundamental indicar se há, entre os ambientes disponíveis, padróes similares de resposta de cultivares (CARVAlHo et al., 2002).

A existência da interação genótipos por ambientes está associada a dois componentes: ela pode ser simples, quando é proporcionada pela diferença de variabilidade entre genótipos nos ambientes, e complexa, quando denota a falta de correlaçáo entre medidas de um mesmo genótipo em ambientes distintos e indica haver inconsistência na superioridade de genótipos com a variação ambiental (Robertson, 1959). Na existência da interação do tipo complexa, a recomendação não pode ser a mesma para todos os ambientes, o que dificulta o lançamento de novas cultivares.

Dessa forma, este trabalho teve como objetivo avaliar a eficiência de seleção das progênies de cafeeiros derivadas de Catuaí com Icatu e descendentes de Híbrido de Timor, por meio da avaliaçáo do índice de coincidência pelo método proposto por Hamblin e ZimmermanN (1986) e da estimação da magnitude da interação progênies $\mathrm{x}$ ambientes e sua decomposição em parte simples e complexa utilizando o método proposto por Cruz e Castoldi (1991).

\section{MATERIAL E MÉTODOS}

Foram avaliadas 18 progênies de cafeeiro em geração $F_{5}$ (Tabela 1), oriundas do cruzamento das cultivares Catuaí Vermelho e Catuaí Amarelo com Icatu e com Híbrido de Timor, obtidas pelo Programa de Melhoramento Genético do Cafeeiro em Minas Gerais, coordenado pela Epamig/
UFLA/UFV. As progênies foram selecionadas com base em produção na Fazenda Ouro Verde, em Campos Altos, e a colheita realizada para abertura de famílias através da mistura de sementes (MS).

Os experimentos foram instalados, em dezembro de 2005, em Lavras, Campos Altos e Patrocínio, compreendendo as duas principais regióes produtoras de café do Estado de Minas Gerais, Sul de Minas e Alto Paranaíba (Tabela 2). Para todos os ensaios, o delineamento utilizado foi de blocos inteiramente casualizados com três repetiçõos no espaçamento de 3,5 x 0,70 m e parcelas de dez plantas. A instalação e o manejo dos experimentos foram feitos de acordo com as recomendações técnicas apropriadas para a cultura do cafeeiro. As adubações foram realizadas conforme exigência e manejo usualmente empregados na cultura para cada regiáo.

Foram avaliadas as seguintes características agronômicas, com base na média dos dados das duas primeiras safras 2007/2008 e 2008/2009 (biênio): (a) produtividade: foi realizada a colheita dos frutos (litros de "café da roça"), em julho de cada ano, e depois a conversão para sacas ha ${ }^{-1}$, considerando o rendimento dos genótipos, calculado por meio de uma amostra de 3 litros de "café da roça" coletada na ocasião da colheita; (b) percentual de "peneira 17 acima": o café foi classificado quanto ao formato do grão e à sua granulometria, ou seja, chato graúdo. Uma amostra de 300 gramas de café beneficiado foi passada pelo conjunto de peneiras 19/18 e 17, sendo expressa a porcentagem de grãos retidos em peneira "17 acima" (peneiras altas); (c) percentual de frutos cereja: foram avaliadas anualmente por ocasião da colheita, por meio da amostragem de frutos das quatro plantas centrais de cada parcela (um litro por parcela), em ramos plagiotrópicos localizados nos

Tabela 1. Relação das progênies (e seus genitores) avaliadas em três locais (Lavras, Campos Altos e Patrocínio) no Estado de Minas Gerais

\begin{tabular}{|c|c|c|}
\hline N.o & Identificação & Genitores \\
\hline 1 & Catucaí Vermelho - MS cv 01 & Icatu e Catuaí Vermelho \\
\hline 2 & Catucaí Vermelho - MS cv 02 & Icatu e Catuaí Vermelho \\
\hline 3 & Catucaí Vermelho - MS cv 03 & Icatu e Catuaí Vermelho \\
\hline 4 & Catucaí Amarelo - MS cv 01 & Icatu e Catuaí Amarelo \\
\hline 5 & Catucaí Amarelo - MS cv 02 & Icatu e Catuaí Amarelo \\
\hline 6 & Catucaí Amarelo - MS cv 03 & Icatu e Catuaí Amarelo \\
\hline 7 & Catucaí Amarelo - MS cv 04 & Icatu e Catuaí Amarelo \\
\hline 8 & Catucaí Amarelo - MS cv 05 & Icatu e Catuaí Amarelo \\
\hline 9 & H516-2-1-1-18 MS cv 01 & Catuaí amarelo e Hibrido de Timor \\
\hline 10 & H516-2-1-1-18 MS cv 02 & Catuaí amarelo e Hibrido de Timor \\
\hline 11 & H516-2-1-1-18 MS cv 03 & Catuaí amarelo e Hibrido de Timor \\
\hline 12 & H516-2-1-1-18 MS cv 04 & Catuaí amarelo e Hibrido de Timor \\
\hline 13 & H516-2-1-1-18 MS cv 05 & Catuaí amarelo e Hibrido de Timor \\
\hline 14 & H419-3-4-5-2 MS cv 01 & Catuaí amarelo e Hibrido de Timor \\
\hline 15 & H419-3-4-5-2 MS cv 02 & Catuaí amarelo e Hibrido de Timor \\
\hline 16 & H419-3-4-5-2 MS cv 03 & Catuaí amarelo e Hibrido de Timor \\
\hline 17 & H419-3-4-5-2 MS cv 04 & Catuaí amarelo e Hibrido de Timor \\
\hline 18 & H419-3-4-5-2 MS cv 05 & Catuaí amarelo e Hibrido de Timor \\
\hline
\end{tabular}


Tabela 2. Descrição das características de clima e solo dos três municípios de avaliação das progênies de cafeeiro

\begin{tabular}{|c|c|c|c|c|}
\hline Município & $\begin{array}{l}\text { Região } \\
\text { do } \\
\text { Estado }\end{array}$ & $\begin{array}{c}\text { Altitude } \\
\text { (m) }\end{array}$ & $\begin{array}{l}\text { Temperatura } \\
\text { média anual } \\
\left({ }^{\circ} \mathrm{C}\right)\end{array}$ & $\begin{array}{l}\text { Precipitação } \\
\text { pluvial } \\
\text { média } \\
\text { anual (mm) }\end{array}$ \\
\hline Lavras & $\begin{array}{l}\text { Sul de } \\
\text { Minas }\end{array}$ & 919 & 19,3 & 1529 \\
\hline $\begin{array}{l}\text { Campos } \\
\text { Altos }\end{array}$ & $\begin{array}{l}\text { Alto do } \\
\text { Paranaíba }\end{array}$ & 1230 & 17,6 & 1830 \\
\hline Patrocínio & $\begin{array}{l}\text { Alto do } \\
\text { Paranaíba }\end{array}$ & 966 & 22,0 & 1620 \\
\hline
\end{tabular}

quatro quadrantes. Foi realizada a contagem dos frutos cereja, sendo expressa em percentual.

Realizou-se a análise individual para todas as características em cada local e após a constatação da homogeneidade das variâncias, por meio do teste de Hartley, como sugerido por Ramalho et al. (2005), realizou-se a análise conjunta considerando a combinaçáo de dois ambientes para todas as características. As análises foram feitas utilizando-se o programa computacional "Genes" (Cruz, 2006).

Para avaliar a eficiência da seleçâo das progênies, foi estimado o índice de coincidência (IC) para diferentes intensidades de seleçáo (IS) utilizadas (16,7\% e 33,3\%), ou seja, a proporção de progênies superiores com o mesmo comportamento para os três ambientes e para as características avaliadas, desconsiderando o efeito do acaso. Para o cálculo, foram utilizadas apenas as 18 progênies, sendo aplicada a expressão de Hamblin e Zimmermann (1986):

$$
I C=\frac{A-C}{M-C} \times 100
$$

\section{Em que:}

$C$ : número de progênies superiores selecionadas, devido ao acaso. Assume-se que o número de progênies superiores selecionado, uma proporção igual à intensidade de seleção coincida por acaso, ou seja: se das 18 progênies, decidiu-se selecionar 16,7\% (ou três indivíduos), 16,7\% destes três $(0,5)$ váo coincidir devido ao acaso. $\mathrm{O}$ índice de coincidência foi aplicado para o comportamento das progênies entre os locais;

$A$ : número de progênies superiores selecionadas, comum aos diferentes ambientes;

$M$ : número de progênies superiores selecionadas em um dos ambientes ou características.

Foi verificada a eficiência de seleção utilizando o método de seleção simultânea, somatório $\mathrm{Z}$ das variáveis padronizadas (Mendes et al., 2009). Nesse método, os dados de produtividade, percentual de peneira 17 e acima e percentual de frutos cereja foram padronizados, visando torná-los diretamente comparáveis. A variável $Z_{\mathrm{ij}}$ foi estimada pelo estimador:

$$
Z_{i j}=\frac{x_{i j}-m_{j}}{S \cdot j}
$$

Em que:

$\mathrm{Z}_{\mathrm{ij}}$ : valor da variável padronizada corresponde ao indivíduo $i$ na repetição $j$;

$\mathrm{x}_{\mathrm{ij}}$ : valor observado da característica considerada do indivíduo $i$ na repetição $j$;

m . j: média de todos os tratamentos na repetição $j$;

s . j: desvio-padrão fenotípico da média na repetição $j$ (RAmalho et al., 2005).

Como a variável $\mathrm{Z}$ pode assumir tanto valores positivos como negativos, foi somada uma constante de valor três, de modo a tornar os valores sempre positivos.

Foi estimada a magnitude da interação progênies $\mathrm{x}$ ambientes e sua decomposição em parte simples e complexa utilizando o método proposto por Cruz e CASTOLDI (1991), cuja parte complexa é expressa por meio da equação:

$$
C=\sqrt{(1-r)^{3} \times Q 1 \times Q 2}
$$

Em que:

$C$ : valor da parte complexa da interação progênies $\mathrm{x}$ ambientes;

$r$ : coeficiente de correlação simples entre progênies nos dois ambientes;

Q1: maior quadrado médio entre progênies nos dois ambientes;

Q2: menor quadrado médio entre progênies nos dois ambientes.

\section{RESULTADOS E DISCUSSÃO}

Para se comparar a eficiência da seleção das progênies, foi estimado o índice de coincidência, que determina a proporçáo de progênies superiores com o mesmo comportamento nos ambientes Lavras, Campos Altos e Patrocínio, para as características produtividade, porcentagem de grâos retidos em peneira "17 acima" e porcentagem de frutos cereja, desconsiderando o efeito do acaso (Tabela 3). Quanto maior o índice de coincidência entre duas características, maior será a concordância dos resultados entre os ambientes (Pedrozo et al., 2009).

Para a produtividade na maioria das situaçóes, a coincidência entre desempenhos das progênies selecionadas foi pequena, confirmando a presença da interação progênies por ambientes, e a estimativa só foi de maior magnitude quando se compararam os ambientes Campos Altos e Patrocínio. A estimativa de $60 \%$ avaliada para estes ambientes pode ser explicada pela proximidade, sendo os dois municípios pertencentes à mesma região. 
Tabela 3. Estimativas do índice de coincidência (IC) entre os ambientes Lavras (L), Campos Altos (CA) e Patrocínio (P) para as características produtividade, porcentagem de grãos retidos em "peneira 17 acima" e porcentagem de frutos cereja no biênio das progênies de cafeeiro

\begin{tabular}{lcccccccccccc} 
& \multicolumn{4}{c}{ Produtividade $\left(\mathbf{s c} . \mathbf{h a}^{-1}\right)$} & \multicolumn{4}{c}{ "Peneira 17 acima" (\%) } & \multicolumn{4}{c}{ Frutos Cereja (\%) } \\
IS (\%) & L/CA/P & L/CA & L/P & CA/P & L/CA/P & L/CA & L/P & CA/P & L/CA/P & L/CA & L/P & CA/P \\
\hline 16,7 & 0 & 0 & 20 & 60 & 0 & 0 & 60 & 0 & 0 & 0 & 20 & 20 \\
33,3 & 0 & 0 & 0 & 25 & 25 & 50 & 50 & 25 & 0 & 0 & 25 & 0
\end{tabular}

IS: Intensidade de seleçăo.

Tabela 4. Estimativas do índice de coincidência (IC) entre os ambientes Lavras (L), Campos Altos (CA) e Patrocínio (P) para o somatório da estatística $Z$, no biênio das progênies de cafeeiro

\begin{tabular}{lcccc} 
IS (\%) & L/CA/P & L/CA & L/P & CA/P \\
\hline 16,7 & 0 & 0 & 20 & 20 \\
33,3 & 25 & 0 & 50 & 50
\end{tabular}

IS: Intensidade de seleçăo.

Para porcentagem de grãos retidos em peneira " 17 acima", na intensidade de seleção de $16,7 \%$, na maioria das situaçôes, não houve coincidência entre os ambientes, ocorrendo estimativa de 60\% somente para Lavras/ Patrocínio. Quando se faz uma seleção mais branda, com intensidade de 33,3\%, houve incremento nas estimativas dos índices de coincidência para a característica porcentagem de grãos retidos em peneira "17 acima". Para a característica porcentagem de frutos cereja, novamente não houve coincidência entre os ambientes de estudo, e quando ocorreu, notaram-se baixas estimativas, em torno de $20 \%$ e $25 \%$, conforme se verificou para Lavras/ Patrocínio, em ambas as intensidades de seleção e para Campos Altos/Patrocínio, na intensidade de seleção mais severa.

Para o método de somatório de $Z$, na intensidade de seleção de $16,7 \%$ ocorreu baixa coincidência (20\%) entre os ambientes, apenas para as situaçóes Lavras/Patrocínio e Campos Altos/Patrocínio. Na seleção mais branda, com intensidade de 33,3\%, houve melhora nas estimativas dos índices de coincidência, chegando a 50\% para situaçóes Lavras/Patrocínio e Campos Altos/Patrocínio (Tabela 4). Os resultados evidenciaram redução na eficiência da seleção para a intensidade de seleção de $16,7 \%$ pela utilização do método de seleção simultânea.

$\mathrm{Na}$ análise das progênies coincidentes entre diferentes ambientes para as características produtividade, porcentagem de grãos retidos em peneira "17 acima”, porcentagem de frutos cereja e somatório de $\mathrm{Z}$ (Tabela 5), verificou-se que as progênies $2,6,7,8,10,13$ e 15 foram aquelas de comportamento coincidente para as características nos locais de estudo.

A existência de respostas diferenciadas de genótipos às variaçóes ambientais tem sido frequentemente constatada em várias espécies de plantas cultivadas, e no caso do café não é diferente (WAMATU et al., 2003; CorrêA et al.,
2006; Nascimento et al., 2010). Essa interação reduz a correlaçáo genética e, consequentemente, os ganhos com a seleção na população (Falconer e Mackay, 1996). A interação também dificulta a recomendação de uma, ou de poucas cultivares, para longa faixa de ambientes. Dessa forma, o conhecimento da magnitude e da natureza da interação auxilia na escolha da melhor estratégia de seleção.

Como a coincidência no comportamento das progênies superiores entre os locais para a maioria das características e combinaçốes de locais foi baixa, no presente trabalho, realizou-se o estudo da magnitude e da natureza da interação para as três combinaçóes de ambientes. Com exceção das características "peneira 17 acima" na combinação Campos Altos/Patrocínio (Pen-CA/ PTC) e porcentagem de cereja nas combinaçôes Lavras/ Campos Altos (Cerj- L/CA) e Campos Altos/Patrocínio (Cerj-CA/PTC), a relação entre a variância da interação progênies $\mathrm{x}$ locais e a variância genética entre progênies foi superior a $100 \%$, ou seja, há um predomínio da variância da interação na variância fenotípica total.

Mesmo para aqueles casos em que a interação genótipos $\mathrm{x}$ locais não foi significativa, como a característica "peneira 17 acima" na combinação Lavras/Patrocínio (Pen-L/PTC) e porcentagem de cereja nas combinaçôes Lavras/Patrocínio (Cer-L/PTC), houve predomínio da variância de interação.

Para a característica produtividade nas três situações houve predominância da variância da interação. Para a combinação Lavras/Campos Altos, a estimativa foi considerada zero devido ao fato de a variância da progênie ter sido nula. Uma explicação para predomínio da variância da interação para a característica produtividade é o fato de esse caráter ser controlado por vários genes de pequeno efeito sobre o fenótipo, classificando-o como quantitativo, ou seja, existe forte influência do ambiente na expressão do caráter (FALCONER e MACKAY, 1996).

Devido à grande diferença das características dos ambientes de estudo, houve comportamento instável das progênies avaliadas. A predominância da parte complexa da interação verificada no presente trabalho evidencia uma situação já relatada para outras culturas, envolvendo estudos de interação genótipos $\mathrm{x}$ ambientes, tais como, feijão (Melo et al., 2007), eucalipto (Paludzyszyn Filho et al., 2001, Romaneli e Sebbenn, 2004), soja (Carvalho et al., 2002) e trigo (CArgnin et al., 2006). 
Segundo Vencovsky e Barriga (1992), a quantificação dos fatores que compóe a interação é importante, pois informa ao melhorista sobre o grau de dificuldade no momento da seleção ou da recomendação de cultivares. Quando há predomínio da parte simples o trabalho de seleção é facilitado, pois a classificação genotípica, nos diferentes ambientes não se altera e a seleção pode ser feita na média dos ambientes. Por outro lado, quando a parte complexa é mais expressiva, torna a decisão mais difícil, uma vez que neste caso existem genótipos que são bem adaptados a ambientes específicos.

Pela decomposição, a contribuição da parte complexa variou de $53,3 \%$ a $97,3 \%$ (Tabela 5). Os valores mínimos foram constatados na análise das

Tabela 5. Progênies de cafeeiro coincidentes entre os ambientes Lavras (L), Campos Altos (CA) e Patrocínio (P) para as características produtividade, porcentagem de grãos retidos em "peneira 17 acima", porcentagem de frutos cereja no biênio e somatório de $\mathrm{Z}$

\begin{tabular}{|c|c|c|c|}
\hline IS (\%) & Característica & IC & Progênie \\
\hline 16,7 & Produtividade & $\mathrm{L} / \mathrm{P}$ & 15 \\
\hline 16,7 & Produtividade & $\mathrm{CA} / \mathrm{P}$ & 10 e 13 \\
\hline 33,3 & Produtividade & $\mathrm{CA} / \mathrm{P}$ & 10,13 e 15 \\
\hline 16,7 & Peneira & $\mathrm{L} / \mathrm{P}$ & 15 \\
\hline 33,3 & Peneira & $\mathrm{L} / \mathrm{C} / \mathrm{P}$ & 7,10 e 15 \\
\hline 33,3 & Peneira & L/CA & $7,10,11$ e 15 \\
\hline 33,3 & Peneira & $\mathrm{L} / \mathrm{P}$ & $6,7,10$ e 15 \\
\hline 33,3 & Peneira & $\mathrm{CA} / \mathrm{P}$ & 7,10 e 15 \\
\hline 16,7 & Cereja & $\mathrm{L} / \mathrm{P}$ & 15 \\
\hline 16,7 & Cereja & $\mathrm{CA} / \mathrm{P}$ & 8 \\
\hline 33,3 & Cereja & $\mathrm{L} / \mathrm{P}$ & 2,13 e 15 \\
\hline 16,7 & Somatório de Z & $\mathrm{L} / \mathrm{P}$ & 15 \\
\hline 16,7 & Somatório de Z & $\mathrm{CA} / \mathrm{P}$ & 10 \\
\hline 33,3 & Somatório de Z & $\mathrm{L} / \mathrm{C} / \mathrm{P}$ & 15,10 \\
\hline 33,3 & Somatório de Z & $\mathrm{L} / \mathrm{CA}$ & $13,15,10,2$ \\
\hline 33,3 & Somatório de Z & $\mathrm{L} / \mathrm{P}$ & $10,15,11,2$ \\
\hline 33,3 & Somatório de Z & $\mathrm{CA} / \mathrm{P}$ & $15,2,10$ \\
\hline
\end{tabular}

características produtividade para os ambientes Campos Altos/Patrocínio, e a porcentagem de grãos retidos em peneira "17 acima" para os ambientes Lavras/Patrocínio; as correlaçóes das progênies nos dois ambientes foram acima de 0,45 e com índice de coincidência em pelo menos uma intensidade de seleção, com valores próximos a $60 \%$. Os valores máximos da contribuição da parte complexa, estimados pela decomposição, estiveram associados às demais características nos ambientes estudados, para as quais as correlaçôes lineares entre locais foram as mais baixas, inferiores a 0,35 .

A resposta das progênies de café aos diferentes ambientes evidencia a dificuldade de seleção de genótipos superiores para as três características nos pares de ambientes estudados. Ressalta-se, também, o fato de que o índice de coincidência, para ambas as intensidades de seleçáo, para estas características, não ocorreram ou foram muito baixos, todos próximos a $20 \%$.

Em relação às estimativas dos coeficientes de herdabilidade, houve grande oscilação, variando de 0 a 79,9\%, sendo de baixa magnitude para a maioria das situaçóes, o que indica pouco progresso com a seleção desses caracteres, com exceção da característica "peneira 17 acima" na combinação Lavras/Patrocínio (Tabela 6).

É sabido que o caráter produtividade é muito complexo, sendo altamente influenciado pelo ambiente. Pelos resultados, nas características peneira alta e na porcentagem de cereja, também houve caracteres complexos. Cruz e Regazzi (2001) afirmam que os caracteres mais complexos normalmente têm baixa herdabilidade. Vale destacar que para a situaçáo em que a magnitude da estimativa herdabilidade foi relativamente mais alta ("peneira 17 acima" na combinação Lavras-Patrocínio), observou-se baixa relação entre a variância da interação e a variância de progênies (apenas 3,9\%). Nota-se também, nesta situação, menor porcentagem da parte complexa da interação

Tabela 6. Variância de progênies $\sigma_{\mathrm{p}}^{2}$, variância da interação $\sigma_{\mathrm{pa}^{2}}^{2}$ (quadrado médio da interação $\left(\mathrm{Q} \mathrm{M}_{\mathrm{pxa}}\right.$ ), parte complexa da interação $(\% \mathrm{C})$, correlaçáo linear fenotípica $(\mathrm{r})$, coeficiente de variação ambiental $(\mathrm{CVe} \%)$ e herdabilidade no sentido amplo $\left(\mathrm{h}_{\mathrm{a}}^{2} \%\right)$, obtidos para as características produtividade (Prod.), porcentagem de gráos retidos em "peneira 17 acima” (Pen.) e porcentagem de frutos cereja (Cerj.) nos ambientes Lavras (L), Campos Altos (CA) e Patrocínio (P)

\begin{tabular}{|c|c|c|c|c|c|c|c|c|}
\hline Variáveis & $\sigma_{p}^{2}$ & $\sigma_{\mathrm{pa}}^{2}$ & $\frac{\sigma_{\mathrm{pa}}^{2}}{\sigma_{\mathrm{p}}^{2}}$ & $\mathbf{Q M}_{\mathrm{pxa}}$ & $\% C$ & $r$ & CVe\% & $h_{a}^{2} \%$ \\
\hline Prod.-L/CA & 0,0000 & 38,5863 & 0,00 & $143,4546^{*}$ & 96,06 & $-0,06$ & 15,00 & 0,00 \\
\hline Prod.-L/P & 5,6047 & 32,9584 & 588,04 & $104,3861^{*}$ & 93,64 & 0,12 & 14,28 & 22,33 \\
\hline Prod.-CA/P & 11,5926 & 22,2265 & 191,73 & $94,6741^{*}$ & 53,31 & 0,47 & 17,20 & 44,72 \\
\hline Pen.-L/CA & 5,2410 & 15,9745 & 304,80 & $89,6560^{*}$ & 92,87 & 0,14 & 14,85 & 24,17 \\
\hline Pen.-L/P & 27,6100 & 1,0993 & 3,98 & 31,5886 & 56,66 & 0,67 & 11,35 & 79,92 \\
\hline Pen.-CA/P & 14,8996 & 11,4314 & 76,72 & 80,3691 & 80,06 & 0,35 & 16,67 & 52,10 \\
\hline Cerj.-L/CA & 0,0000 & 17,0711 & 0,00 & 105,6400 & 97,31 & $-0,09$ & 12,42 & 0,00 \\
\hline Cerj. L/P & 7,2613 & 1,4103 & 19,42 & 76,4087 & 80,25 & 0,22 & 17,23 & 34,18 \\
\hline Cerj.-CA/P & 11,7936 & 14,8726 & 126,10 & $127,9734^{*}$ & 87,05 & 0,24 & 16,70 & 38,94 \\
\hline
\end{tabular}

* Interaçáo progênie $\mathrm{x}$ local significativa pelo teste de $\mathrm{F}(\mathrm{p}<0,05)$. 
$(56,6 \%)$ em relaçáo à parte simples quando comparado às outras situaçôes estudadas.

Por esses resultados, nota-se que a magnitude e a contribuição da parte simples e complexa da interaçáo afetam a estimativa da herdabilidade e, consequentemente, os ganhos com a seleção. Esse fato foi constatado por outros autores. MeLo et al. (2006), em trabalho visando estudar o desempenho do clone RB série 94 de cana de açúcar, na região da Mata de Pernambuco, quanto à produtividade agroindustrial, as interaçóes genótipos por ambientes e as magnitudes de alguns parâmetros genéticos, verificaram que para a característica percentual de pureza a estimativa da herdabilidade foi relativamente mais baixa, e para essa característica houve predomínio da variância da interação em relação à de progênies. Da mesma forma, NunEs et al. (2002) atribuem a alta estimativa da herdabilidade observada em trabalho com clones de eucalipto, ao fato de a estimativa do componente da variância da interação ter sido inferior ao componente da variância entre clones. Com objetivo de quantificar o componente da interação genótipos $\mathrm{x}$ ambientes e avaliar seus reflexos no progresso genético com diferentes critérios de seleção nas condições do Brasil Central, CARGNin et al. (2006) verificaram maior porcentagem da parte complexa da interação e constataram que ganhos com a seleção de linhagens de trigo, quando feita de maneira indireta em um ambiente, não são eficientes, especialmente quando se trata da produtividade de grãos.

A estimativa do coeficiente de herdabilidade é influenciada pela precisão experimental e magnitude da variância de progênies. No presente trabalho, considera-se que as baixas magnitudes dos coeficientes de herdabilidade ocorreram em função da predominância da variância da interação em detrimento da variância de progênies. Esse fato pode ser verificado com as estimativas dos coeficientes de variação ambiental das análises de variâncias conjuntas que oscilaram entre 11,35 e 17,23 indicando boa precisão experimental, principalmente considerando trabalhos com a cultura do café em campo (Bonomo et al., 2004; Carvalho et al., 2008).

\section{CONCLUSÃO}

A predominância da parte complexa em relação à simples na interação das progênies $\mathrm{x}$ ambientes confirma a baixa ou não coincidência das progênies nos diferentes ambientes, dificultando uma recomendação generalizada para as diferentes regióes cafeeiras do Estado.

\section{AGRADECIMENTOS}

Ao Conselho Nacional de Desenvolvimento Científico e Tecnológico (CNPq), ao Instituto Nacional de Ciência e
Tecnologia (INCT/Café), ao Consórcio Pesquisa Café e à Fundaçáa de Amparo à Pesquisa do Estado de Minas Gerais (Fapemig), pelo suporte financeiro ao projeto.

\section{REFERÊNCIAS}

BONOMO, P.; CRUZ, C.D.; VIANA, J.M.S.; PEREIRA, A.A.; OLIVEIRA, V.R.; CARGNIN, A; SOUZA, M.A.; CARNEIRO, P.C.S.; SOFIATTI, V. Interação entre genótipos e ambientes e implicações em ganhos com seleção em trigo. Pesquisa Agropecuária Brasileira, v.41, p.987-993, 2006.

CARVALHO, C.G.P.; ARIAS, C.A.A.; TOLEDO, J.F.F.; ALMEIDA, L.A.; KIIHL R.A.S.; OLIVEIRA, M.F. Interação genótipo $\mathrm{x}$ ambiente no desempenho produtivo da soja no Paraná. Pesquisa Agropecuária Brasileira, v.37, p.989-1000, 2002.

CARVALHO, A.M.; PEREIRA, A.A., CARVALHO, G.R., MENDES, A.N.G., BOTELHO, C.E. Avaliação de progênies de cafeeiros obtidas do cruzamento entre Catuaí e Híbrido de Timor. Scientia Agraria, v.9, p.249-253, 2008.

CRUZ, C.D.; CASTOLDI, F.L. Decomposiçấo da interação genótipos $\mathrm{x}$ ambientes em partes simples e complexa. Revista Ceres, v.38, p.422-430. 1991.

CRUZ, C.D.; REGAZZI, A.J. Modelos biométricos aplicados ao melhoramento genético. Viçosa: Editora UFV, 2001. 390p.

CRUZ, C.D. Programa Genes: Biometria. Viçosa: Editora UFV, 2006. 382p.

FALCONER, D.S.; MACKAY, T.F.C. Introduction to quantitative genetics. London: Longman, 1996. 463p.

HAMBLIN, J.E.; ZIMMERMANN, M.J.O. Breeding common bean for yield in mixtures. Plant Breeding Reviews, v.4, p.245-272. 1986.

MENDES, F.F.; RAMALHO, M.A.P;; ABREU, A.F. Índice de seleção para escolha de populações segregantes do feijoeiro-comum. Pesquisa Agropecuária Brasileira, v.44, p.1312-1318, 2009.

MELO, L.J.T.; OLIVEIRA, FJ.; BASTOS, Q.B.; ANUNCIAÇÃO FILHO C.J.; REIS, O.V. Interaçấo genótipos x ciclos de colheita de cana de açúcar da Zona da Mata Norte Pernambuco. Bragantia, v.41, p.197-205. 2006.

MELO, L.C.; SANTOS, P.G.; FARIA, L.C.; DIAZ, J.L.C.; DEL PELOSO, M.J.; RAVA, C.A.; COSTA, J.G.C. Interaçáo com ambientes e estabilidade de genótipos de feijoeiro-comum na Regiáo Centro-Sul do Brasil. Pesquisa Agropecuária Brasileira, v.42, p.715-723, 2007.

NASCIMENTO, M.; FERREIRA, A.; FERRÃO, R.G.; CAMPANA, A.C.M.; BHERING, L.L.; CRUZ, C.D.; FERRÃO, M.A.G.; FONSECA, A.F.A. Adaptabilidade e estabilidade via regressão não paramétrica em genótipos de café. Pesquisa Agropecuária Brasileira, v.45, p.41-48, 2010.

NUNES, G.H.S; REZENDE, G.; RAMALHO, M.A.; SANTOS, J. Implicaçôes da interação genótipos $x$ ambientes na seleção de clones de eucalipto. Cerne, v.8, p.49-58, 2002. 
PALUDZYSZYN FILHO, E.; MORA, A.L., MAESTRI, R. Interação de genótipos de Pinstaeda L. com locais no Sul-Sudeste do Brasil. Cerne, v.7, p.90-100, 2001.

ROBERTSON A. Experimental design on the measurement of heritabilities and genetic correlations: biometrical genetics. New York: Pergamon, 1959. 186p.

RAMALHO, M.A.P.; FERREIRA, D.F.; OLIVEIRA, A.C. A experimentaçáo em genética e melhoramento de plantas. Lavras: Editora UFLA, 2005. 300p.

SILVA, F.L.; SOARES, P.C.; CARGNIN, A.; SOUZA, M.A.; SOARES, A.A.; CORNÉLIO, V.M.O.; REIS, M.S. Methods of adaptability and stability analysis in irrigated rice genotypes in
Minas Gerais, Brazil. Crop Breeding and Applied Biotechnology, v.8, p.119-126, 2008.

VASCONCELOS, E.S.; REIS, M.S.; CRUZ, C.D.; SEDIYAMA, T.; SCAPIM, C.A. Adaptability and stability of semilate and late maturing soybean genotypes in Minas Gerais state. Acta Scientiarum. Agronomy, v.32, p.411-415, 2010.

VENCOVSKY R.; BARRIGA P. Genética biométrica no fitomelhoramento. Ribeirão Preto: Sociedade Brasileira de Genética, 1992. $496 \mathrm{p}$.

WAMATU, J.N.; THOMAS, E.; PIEPHO, H.P. Responses of different arabica coffee (Coffea arabica L.) clones to varied environment conditions. Euphytica, v.129, p.175-182, 2003. 